\title{
Variable Threshold of Trigeminal Cold-Thermosensitive Neurons Is Determined by a Balance between TRPM8 and Kv1 Potassium Channels
}

\author{
Rodolfo Madrid, ${ }^{1,2 *}$ Elvira de la Peña, ${ }^{1 *}$ Tansy Donovan-Rodriguez, ${ }^{1}$ Carlos Belmonte, ${ }^{1}$ and Félix Viana ${ }^{1}$ \\ ${ }^{1}$ Instituto de Neurociencias de Alicante, Universidad Miguel Hernández-Consejo Superior de Investigaciones Científicas, 03550 San Juan de Alicante, Spain, \\ and 2Departamento de Biología, Facultad de Química y Biología, Universidad de Santiago de Chile, Santiago 9160000, Chile
}

\begin{abstract}
Molecular determinants of threshold differences among cold thermoreceptors are unknown. Here we show that such differences correlate with the relative expression of $I_{\mathrm{KD}}$, a current dependent on Shaker-like Kv1 channels that acts as an excitability brake, and $I_{\mathrm{TRPM}}$, a cold-activated excitatory current. Neurons responding to small temperature changes have high functional expression of TRPM8 (transient receptor potential cation channel, subfamily $\mathrm{M}$, member 8 ) and low expression of $I_{\mathrm{KD}}$. In contrast, neurons activated by lower temperatures have a lower expression of TRPM8 and a prominent $I_{\mathrm{KD}}$. Otherwise, both subpopulations have nearly identical membrane and firing properties, suggesting that they belong to the same neuronal pool. Blockade of $I_{\mathrm{KD}}$ shifts the threshold of cold-sensitive neurons to higher temperatures and augments cold-evoked nocifensive responses in mice. Similar behavioral effects of $I_{\mathrm{KD}}$ blockade were observed in TRPA1 ${ }^{-1-}$ mice. Moreover, only a small percentage of trigeminal cold-sensitive neurons were activated by TRPA1 agonists, suggesting that TRPA1 does not play a major role in the detection of low temperatures by uninjured somatic cold-specific thermosensory neurons under physiological conditions. Collectively, these findings suggest that innocuous cooling sensations and cold discomfort are signaled by specific low- and high-threshold cold thermoreceptor neurons, differing primarily in their relative expression of two ion channels having antagonistic effects on neuronal excitability. Thus, although TRPM8 appears to function as a critical cold sensor in the majority of peripheral sensory neurons, the expression of Kvl channels in the same terminals seem to play an important role in the peripheral gating of cold-evoked discomfort and pain.
\end{abstract}

\section{Introduction}

Low external temperatures can evoke a variety of perceptual sensations that include pleasant cool feelings, unpleasant cold sensations, and overt pain (Hensel, 1981; Morin and Bushnell, 1998; Davis and Pope, 2002). There is a general consensus that cold sensations evoked by non-noxious temperatures and painful sensations evoked by strong cold involve activation of separate subsets of low- and high-threshold cold-sensitive fibers (reviewed by Green, 2004; Reid, 2005). However, the cellular and molecular mechanisms underlying the marked differences in thermal threshold among cold sensory afferents have not been clarified yet. One model contends that TRPM8 (transient receptor potential cation channel, subfamily $M$, member 8), a nonselective, calcium-permeable, cation chan-

\footnotetext{
Received 0ct. 2, 2008; revised Jan. 28, 2009; accepted Feb. 6, 2009.

This work was supported by funds from the Spanish Ministry of Education and Science: Projects BFU2007-61855 to F.V., and BFU2005-08741 and CONSOLIDER-INGENI0 2010 CSD2007-00023 to C.B., and the Spanish Fundación Marcelino Botín. We thank E. Quintero, A. Miralles, and A. Pérez Vergara for skilful technical assistance and S. Ingham for artwork. The TRPA1 ${ }^{-1-}$ mice used were a generous gift from Dr. D. Corey and Dr. K. Y. Kwan (Harvard Medical School, Boston, MA). We thank Prof. A. Harvey for advice on handling of dendrotoxins. We acknowledge A. Mälkiä, R. Gallego, and M. Domínguez for suggestions and comments on this manuscript.

*R.M. and E.d.I.P. contributed equally to this work.

Correspondence should be addressed to Dr. Félix Viana, Universidad Miguel Hernández, Instituto de Neurociencias-CSIC, Apartado 18, San Juan de Alicante, 03550 Spain. E-mail: felix.viana@umh.es. D0I:10.1523/JNEUROSCI.4778-08.2009

Copyright $\odot 2009$ Society for Neuroscience $\quad 0270-6474 / 09 / 293120-12 \$ 15.00 / 0$
}

nel that is activated by cooling and menthol (McKemy et al., 2002; Peier et al., 2002), is responsible for innocuous cold sensing, whereas a second TRP channel, TRPA1, is activated by noxious cold (Story et al., 2003; Sawada et al., 2007). However, the activation of TRPA 1 by cold is controversial (Bautista et al., 2005; Reid, 2005; Zurborg et al., 2007), and some recent behavioral, structural, and genetic studies support the view that TRPM8 could be the principal determinant of the responsiveness of a thermoreceptor to innocuous and noxious cold (Bautista et al., 2007; Colburn et al., 2007; Dhaka et al., 2007; Green and Schoen, 2007; Takashima et al., 2007). Early functional studies characterizing low- and high-threshold coldsensitive neurons also documented a significant overlap in their properties, in particular, menthol sensitivity (Nealen et al., 2003; Thut et al., 2003). The recent description of menthol sensitivity of TRPA1 channels (Karashima et al., 2007) complicates the interpretation of these results. If TRPM8 can function as a temperature sensor for innocuous and noxious cold, an unsolved fundamental question is how a single molecular sensor can operate over such a large range of temperatures.

Additional molecular mechanisms participate in cold detection by peripheral sensory terminals (Reid, 2005; Munns et al., 2007), including rapidly inactivating cation channels of unknown molecular nature (Babes et al., 2006) and thermosensitive leak or background $\mathrm{K}^{+}$channels that are closed by cooling, thereby causing depolarization and impulse firing in sensory 
neurons (Reid and Flonta, 2001; Viana et al., 2002). The importance of these latter mechanisms in discriminating innocuous and unpleasant cold sensations has not been determined yet.

In the present work we explored the molecular mechanisms involved in the determination of threshold to cold stimuli in thermoreceptor neurons, and found that threshold differences are determined by the relative expression of two ion channels, TRPM8 and Shaker-like Kv1 channels, having antagonistic effects on neuronal excitability. These results suggest an important role for Kv1 channels in the peripheral gating of cold-evoked discomfort and pain.

\section{Materials and Methods}

Animals

Studies were performed on neonatal (P1-P6) and adult OF1 mice, or adult TRPA ${ }^{-1-}$ mice generously provided by Dr. D. Corey (Harvard Medical School, Boston, MA). The genotype was established by PCR, using previously published primers (Kwan et al., 2006). All experiments were conducted according to European Community animal use guidelines.

\section{Cell culture}

Trigeminal ganglion (TG) neurons were cultured as described previously (Viana et al., 2001). Ganglia were dissected out and incubated with 1 $\mathrm{mg} / \mathrm{ml}$ collagenase type IA (Sigma) for $45 \mathrm{~min}$ at $37^{\circ} \mathrm{C}$ in $5 \% \mathrm{CO}_{2}$, and cultured in 45\% DMEM, 45\% F-12, 10\% fetal bovine serum (Invitrogen), supplemented with $4 \mathrm{~mm}$ L-glutamine (Invitrogen), $200 \mu \mathrm{g} / \mathrm{ml}$ streptomycin, $125 \mu \mathrm{g} / \mathrm{ml}$ penicillin, $17 \mathrm{~mm}$ glucose, and nerve growth factor (NGF) (mouse 7S, $100 \mathrm{ng} / \mathrm{ml}$; Sigma). Cells were plated on polyL-lysine-coated glass coverslips and used after $1-2 \mathrm{~d}$ in culture.

\section{$\mathrm{Ca}^{2+}$ imaging}

Neurons were incubated with $5 \mu \mathrm{M}$ fura-2 AM dissolved in standard extracellular solution and $0.02 \%$ Pluronic (Invitrogen) for $45 \mathrm{~min}$ at $37^{\circ} \mathrm{C}$. Fluorescence measurements were made with a Leica DM IRE2 inverted microscope fitted with a 12-bit cooled CCD camera (Imago QE Sensicam, Till Photonics). fura-2 was excited at 340 and $380 \mathrm{~nm}$ with a Polychrome IV monochromator (Till Photonics), and the emitted fluorescence was filtered with a $510 \mathrm{~nm}$ longpass filter. Calibrated ratios $(0.5$ $\mathrm{Hz}$ ) were displayed online with TillVision software v4.01 (Till Photonics). Bath temperature was sampled simultaneously (see below), and threshold temperature values for $\left[\mathrm{Ca}^{2+}\right]_{\mathrm{i}}$ elevation were estimated by linearly interpolating the temperature at the midpoint between the last baseline point and the first point at which a rise in $\left[\mathrm{Ca}^{2+}\right]_{\mathrm{i}}$ deviated by at least four times the SD of the baseline.

We have shown previously a very tight correlation between threshold temperature detected on the $\left[\mathrm{Ca}^{2+}\right]_{\mathrm{i}}$ signal and the threshold of action potential firing detected in the cell-attach mode (Viana et al., 2002; Madrid et al., 2006).

\section{Electrophysiology}

Perforated-patch or whole-cell voltage- or current-clamp recordings were performed simultaneously with temperature recordings. The standard bath solution contained (in mM): $124 \mathrm{NaCl}, 5 \mathrm{KCl}, 1.2 \mathrm{KH}_{2} \mathrm{PO}_{4}, 26$ $\mathrm{NaHCO}_{3}, 1 \mathrm{MgCl}_{2}, 2 \mathrm{CaCl}_{2}, 10$ glucose. The solution was continuously bubbled with carbogen $\left(5 \% \mathrm{CO}_{2}+95 \% \mathrm{O}_{2}\right)$ and had a $\mathrm{pH}$ of 7.4. Standard patch-pipettes (4-6 M $\Omega$ resistance) contained (in mM): $140 \mathrm{KCl}, 10$ $\mathrm{NaCl}, 4 \mathrm{Mg}$-ATP, $0.4 \mathrm{Na}$-GTP, 10 HEPES (300 mOsm/kg, pH 7.3 adjusted with $\mathrm{KOH}$ ). During perforated-patch recordings they contained (in $\mathrm{mm}$ ): $105 \mathrm{~K}$-gluconate, $35 \mathrm{KCl}, 10 \mathrm{NaCl}, 10 \mathrm{HEPES}, 0.1 \mathrm{EGTA}$, and 1 $\mathrm{mg} / \mathrm{ml}$ amphotericin B (Sigma). Current and voltage signals were recorded with an EPC-8 patch-clamp amplifier (Heka Elektronik) or with an Axopatch 200B (Molecular Devices). Stimulus delivery and data acquisition were performed using pClamp 9 software (Molecular Devices).

\section{Temperature stimulation}

Coverslip pieces with cultured cells were placed in a microchamber and continuously perfused $(\sim 1 \mathrm{ml} / \mathrm{min})$ with solutions warmed at $34 \pm 1^{\circ} \mathrm{C}$. The temperature was adjusted with a water-cooled Peltier device (model
RDTC-1, ReidDan Electronics), with the outlet close to the imaging field, and controlled by a feedback device. Cold sensitivity was investigated with an $\sim 50$ s duration ramp-like temperature drop to $\sim 19^{\circ} \mathrm{C}$, applied in control solution and in the presence of various drugs.

\section{Experimental protocol}

The first step in the protocol consisted in the determination of the temperature response threshold to a cooling ramp, using the elevation in $\left[\mathrm{Ca}^{2+}\right]_{\mathrm{i}}$. Thereafter, cells were approached with a patch-pipette and, after attainment of the whole-cell configuration, neurons were recorded in whole-cell current-clamp or voltage-clamp mode. In current-clamp mode, neurons were held at $-60 \mathrm{mV}$, and a series of negative and positive depolarizing steps $(\Delta \mathrm{i}=25 \mathrm{pA})$ of $500 \mathrm{~ms}$ duration were delivered to the cell to calculate basic electrophysiological properties: input resistance, rheobase, spike duration, inward rectification, and firing pattern. In voltage clamp, the neurons were initially held at $-50 \mathrm{mV}$. A $500 \mathrm{~ms}$ hyperpolarizing pulse to $-120 \mathrm{mV}$ was used to estimate $I_{\mathrm{h}}$. The slow outward current, measured $1 \mathrm{~s}$ after the return to $-50 \mathrm{mV}(-40 \mathrm{mV}$ in a second set of experiments) was taken as $I_{\mathrm{KD}}$. Thereafter, cells were held at -60 $\mathrm{mV}$ and cooled from $34 \pm 1^{\circ} \mathrm{C}$ to $\sim 20^{\circ} \mathrm{C}$. The difference between holding current at both temperatures is the cold-sensitive current $\left(I_{\text {cold }}\right)$. $I_{\text {TRPM8 }}$ was taken as the inward current potentiated by $100 \mu \mathrm{M}$ menthol at $20^{\circ} \mathrm{C}$.

To characterize $I_{\mathrm{KD}}$ in more detail, we used standard activation and inactivation pulse protocols combined with pharmacological manipulations. The current-voltage $(I-V)$ relationship for the total $\mathrm{K}^{+}$current was determined from a series of depolarizing voltage steps (1.5 s duration) between -70 and $+60 \mathrm{mV}$, in $10 \mathrm{mV}$ increments, delivered at a rate of $0.1 \mathrm{~Hz}$, in the presence of $0.5 \mu \mathrm{M}$ TTX. Pulses were delivered from the holding potential of $-50 \mathrm{mV}$ or after a prepulse $(0.5 \mathrm{~s})$ to $-120 \mathrm{mV}$. This protocol was repeated in the presence of $100 \mu \mathrm{M} 4$-AP. The inactivation protocol consisted of a fixed pulse to $0 \mathrm{mV}(1.4 \mathrm{~s})$ preceded by a variable prepulse ( $0.5 \mathrm{~s}$ duration) between -120 and $-10 \mathrm{mV}$, in $10 \mathrm{mV}$ increments, delivered at a rate of $0.1 \mathrm{~Hz}$.

\section{Data analysis}

The 4-AP-sensitive current (i.e., $I_{\mathrm{KD}}$ ) was obtained by digital subtraction of the records to the same potential before and after application of the drug at $100 \mu \mathrm{M}$.

Conductance-voltage $(G-V)$ curves were constructed from the $I-V$ curves of individual neurons by dividing the evoked current by the driving force, according to the following equation: $G=I /\left(V_{\mathrm{m}}-V_{\text {rev }}\right)$, where $V_{\mathrm{m}}$ is the testing potential and $V_{\text {rev }}$ is the theoretical reversal potential of the current determined from the Nernst equation for $\mathrm{K}^{+}$ions.

Steady-state activation and inactivation data were fitted with a Boltzmann function: $G=G_{\max } /\left(1+\exp \left[\left(V_{1 / 2}-V\right) / s\right]\right)$, where $G$ is the observed whole-cell conductance, $G_{\max }$ is the fitted maximal conductance, $V_{1 / 2}$ is the potential for half-maximal activation, and $s$ is the slope factor. Data were subsequently normalized to $G_{\max }$.

Data are reported as mean \pm SEM. Statistical significance $(p<0.05)$ was assessed by Student's $t$ test.

\section{Behavioral assays}

Thirty-one adult male wild-type OF1 mice $(36.3 \pm 0.4 \mathrm{~g})$ and 17 adult TRPA1 knock-out mice $(31.1 \pm 0.7 \mathrm{~g}$ ) (Kwan et al., 2006) were used in the behavioral studies. Animals were housed six per cage, maximum, on a $12 \mathrm{~h} \mathrm{light/dark} \mathrm{cycle} \mathrm{(all} \mathrm{experiments} \mathrm{performed} \mathrm{in} \mathrm{light)} \mathrm{with} \mathrm{food} \mathrm{and}$ water ad libitum. Mice were habituated to the behavior room for a minimum of $3 \mathrm{~h}$ before testing and to the testing chambers for at least $1 \mathrm{~h}$ before testing. The same investigator performed the scoring in all of the behavioral tests, which were performed blind with respect to the different solutions injected.

Acetone testing. For acetone-evoked evaporative cooling, mice were placed in round plastic chambers on a metal mesh platform. A drop $(\sim 50$ $\mu \mathrm{l})$ of acetone was applied to the plantar surface of the left and right hindpaws, and the number of each of the following nocifensive events was counted over the next $60 \mathrm{~s}$ : lifting, licking, biting, shaking, and guarding. At least 5 min separated testing on the left and right hindpaws. The number of events counted for the contralateral paw (opposite paw to that which will receive injection) was subtracted from that for the ipsilateral paw to give the acetone score; thus, a value close to zero indicates no 
difference between cold-evoked sensations of the ipsilateral and contralateral hindpaws, whereas a highly positive value indicates cold allodynia, and a highly negative value indicates cold hypoalgesia in the injected hindpaw.

Cold plate testing. The temperature of the cold plate was maintained at $0 \pm 0.5^{\circ} \mathrm{C}$ by a feedback-controlled Peltier device. Mice were placed on the cold plate, and the latency to one of the following nocifensive behaviors was measured with a cutoff of $60 \mathrm{~s}$ to avoid tissue injury: licking, biting, lifting, guarding, or shaking of the hindpaws, or jumping.

Hot plate testing. The temperature of the hot plate was maintained at $52 \pm 0.5^{\circ} \mathrm{C}$ and the latencies to nocifensive behavior were measured as described above for the cold plate test.

Mechanical threshold. Thresholds (in millinewtons) to punctate mechanical stimuli were determined using calibrated von Frey monofilaments applied to the plantar side of the hindpaw according to a modified version of the Dixon up-down paradigm (Chaplan et al., 1994).

To establish baseline values, two acetone, cold plate, hot plate, and von Frey threshold tests were performed with a minimum of $2 \mathrm{~h}$ between each testing period before injection of drug or vehicle. The means of the two baseline responses were calculated for comparison with postinjection values.

Solutions, either drug or solvent, were injected into the plantar surface of the hindpaw in a volume of $10 \mu$ l using a 30 gauge needle coupled to a Hamilton syringe. In the 10 (4-AP) or $20 \mathrm{~min}[\alpha$-dendrotoxin $(\alpha$-DTx)] after injection, nocifensive behavior (licking, biting, shaking, lifting, and guarding of the hindpaws) was measured as time spent in seconds performing these actions during each minute of the observation period. The nocifensive behaviors provoked by injection subsided within this period. The acetone and cold plate tests were then repeated in the animals and the values obtained were compared with the mean of the baseline responses.

\section{Reagents}

4-(3-Chloro-pyridin-2-yl)-piperazine-1-carboxylic acid (4-tert-butylphenyl)-amide (BCTC) was a generous gift from Grünenthal AG. L-Menthol was purchased from Scharlau Chemie. TTX citrate, 4-AP, allyl isothiocyanate (AITC), capsaicin, and tetraethylammonium (TEA) were purchased from Sigma-Aldrich. $\alpha$-Dendrotoxin, dendrotoxin K (DTx$\mathrm{K})$, and tityustoxin-K $\alpha$ (TsTx) were purchased from Alomone.

\section{Results}

\section{Cold-sensitive neurons display different} temperature thresholds

The threshold of cold-sensitive (CS) trigeminal sensory neurons in culture, identified with intracellular calcium imaging (Fig. $1 A)$, varies over a wide range as evidenced when two CS neurons are recorded simultaneously (Fig. $1 B$ ) (see also Thut et al., 2003). Figure $1 C$ shows the distribution of threshold temperatures in a large population of CS trigeminal neurons $(n=393)$ during temperature ramps down to $19^{\circ} \mathrm{C}$. Because of pronounced thermal gradients across the skin, this range of temperatures (from 35 to $19^{\circ} \mathrm{C}$ ) in culture covers those values to which intracutaneous sensory nerve endings of humans are subjected in vivo, even during maintained surface exposure to noxious cold temperatures (Morin and Bushnell, 1998; Mauderli et al., 2003). We considered low-threshold CS neurons (LT-CS) those with a threshold temperature $>26.5^{\circ} \mathrm{C}$. They represented $75 \%$ of the population (mean threshold $=31.30 \pm 0.01^{\circ} \mathrm{C}$ ). The high-threshold CS neurons (HT-CS) were less frequent $(25 \%$; mean threshold = $\left.24.20 \pm 0.03^{\circ} \mathrm{C}\right)$.
The two, operationally defined subpopulations of CS neurons were indistinguishable in terms of their basic electrophysiological characteristics (supplemental Fig. S1, available at www.jneurosci.org as supplemental material) and distinct from other functional classes of sensory neurons such as low threshold mechanoreceptor or polymodal nociceptor neurons (Perl, 1996; Viana et al., 2001; Lawson, 2002).

TRPA1 channels are not the main determinants of cold detection within innocuous and unpleasant cold temperature ranges in trigeminal neurons

TRPA1 is a contested sensor of noxious cold (Story et al., 2003; Jordt et al., 2004; Obata et al., 2005; Bautista et al., 2006; Sawada et al., 2007; Zurborg et al., 2007). To reliably determine cold sensitivity in TRPA1-expressing TG neurons, we identified this population using AITC, a pungent compound that activates TRPA1 channels selectively (Bandell et al., 2004; Jordt et al., 2004). The great majority, 61 of 66 , of AITC-sensitive adult TG neurons lacked responses during cooling ramps to $\sim 19^{\circ} \mathrm{C}$ (Fig. $2 A)$. Only five neurons were activated by these ramps ( $1 \mathrm{LT}, 4$ HT). As a matter of fact, cooling produced a significant $(p<$ 0.001 ) inhibition of the AITC-evoked $\left[\mathrm{Ca}^{2+}\right]_{\mathrm{i}}$ signal (Fig. $2 \mathrm{~A}, B$ ).

To explore the possibility that some of the CI neurons had a thermal threshold below $19^{\circ} \mathrm{C}$, we applied stronger cooling stimuli $\left(\sim 8^{\circ} \mathrm{C}\right)$ to 166 neurons that were originally classified as $\mathrm{CI}$ when cooled to $\sim 19^{\circ} \mathrm{C}$ (Fig. $2 C-E$ ). Of those, 8 became CS at this lower temperature. Two of the eight were insensitive to AITC and potentiated by menthol, resembling HT-CS neurons (Fig. 2C). The other six were sensitive to AITC, menthol, and capsaicin, a phenotype characteristic of polymodal nociceptors probably expressing TRPA1 channels (Jordt et al., 2004; Fajardo et al., 2008). Interestingly, we noted that cooling inhibited the responses to menthol and AITC in these neurons (Fig. 2D). The same double cooling step protocol was applied to neurons derived from TRPA1 ${ }^{-1-}$ mice (Fig. $\left.2 F-H\right)$. As expected, none of them responded to AITC. In TRPA $1^{-1-}$ mice, 8 of 160 neurons insensitive to cooling down to $19^{\circ} \mathrm{C}$ responded to cooling to $\sim 8^{\circ} \mathrm{C}$ : in 5 

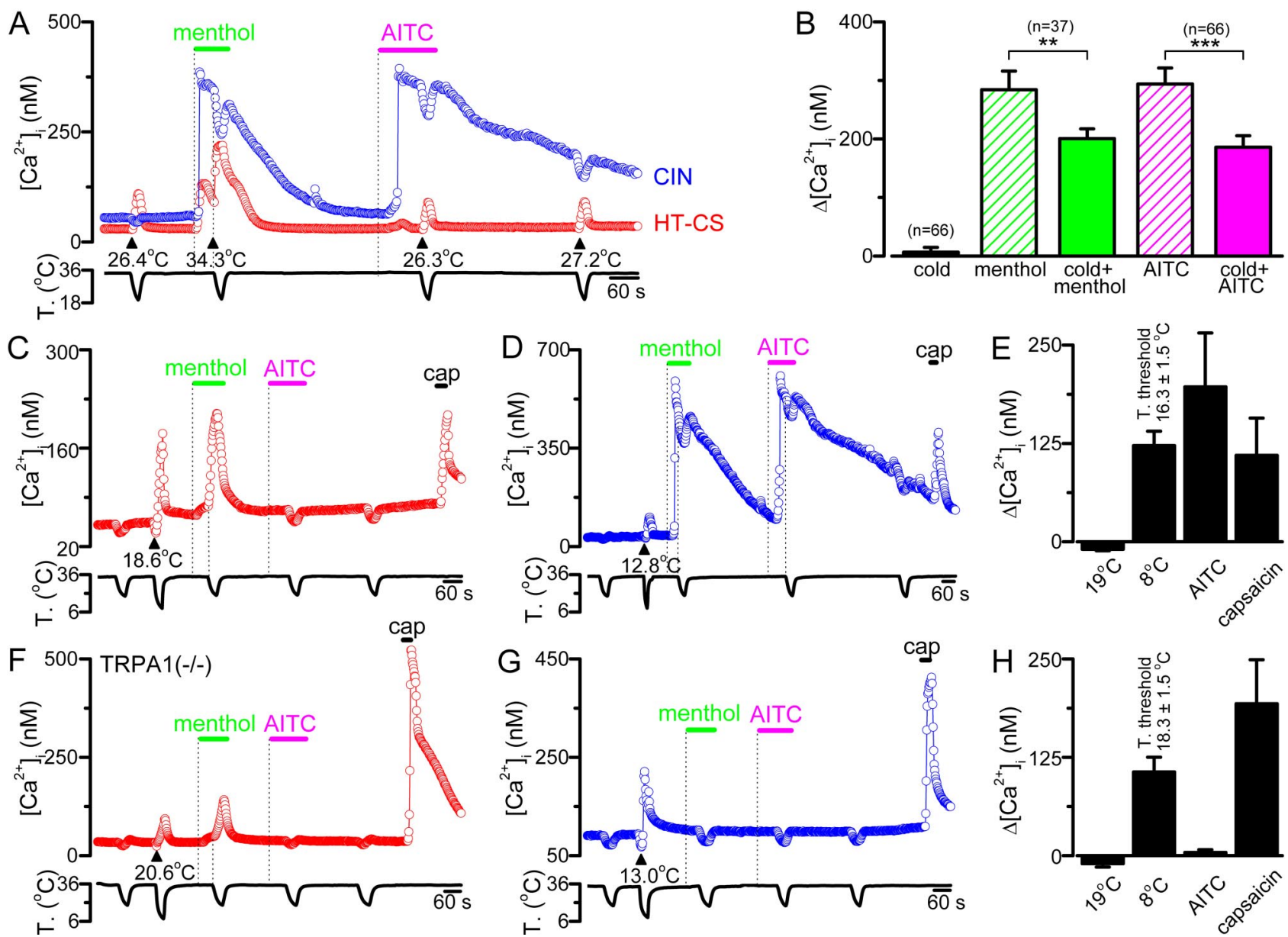

Figure 2. TRPA1 does not mediate low- and high-threshold cold responses in TG neurons. $A$, Protocol used to evaluate the cold sensitivity of TRPA1-expressing neurons. A microscopic field containing at least one (S neuron (red trace) was bathed in menthol (100 $\mu \mathrm{M}$ ) followed by the specific TRPA1 agonist AITC (100 $\mu \mathrm{M})$. During the perfusion of chemical agonists, a cooling pulse similar to the one in control solution was applied. Note the marked inhibition in the chemically evoked $\left[\mathrm{Ca}^{2+}\right]_{\text {i }}$ responses during the cooling pulse, observed only in the AlTC-responding cell. $\boldsymbol{B}$, Bar histogram summarizing the effect of cold and chemical agonists (100 $\mu \mathrm{m}$ menthol or $100 \mu \mathrm{M} \mathrm{AITC}$ ) on $\left[\mathrm{Ca}^{2+}\right]_{\mathrm{i}}$ responses in AITC-sensitive neurons. Note the lack of significant cold responses in this subpopulation of neurons. C, Protocol used to investigate the phenotype of neurons activated by very low temperatures. Neurons were probed with a cooling pulse to $\sim 19^{\circ} \mathrm{C}$ followed by a second cooling pulse to $\sim 8^{\circ} \mathrm{C}$. Thereafter, neurons were tested for responsiveness to menthol $(100 \mu \mathrm{M})$, AITC $(100 \mu \mathrm{M})$ and capsaicin $(500 \mathrm{~nm})$, at baseline temperature $\left(35^{\circ} \mathrm{C}\right)$ and during a cooling pulse to $\sim 19^{\circ} \mathrm{C}$. Note the lack of response to AITC and the potentiation of the cold-evoked response by menthol. D, Same protocol as in C but in a different neuron. Note the responsiveness of this neuron to the three chemical agonists, and the transient inhibition in the response to menthol and AITC during cooling. $E$, Bar histogram summarizing the effect of the two different cold temperatures and chemical agonists (100 $\mu$ M AITC and $500 \mathrm{~nm}$ capsaicin) on $\left[\mathrm{Ca}^{2+}\right]_{\mathrm{i}}$ responses. The data in $\boldsymbol{F}, \boldsymbol{G}$, and $\boldsymbol{H}$ present the same protocol in neurons from TRPA ${ }^{-1-}$ mice.

of them, the cold-evoked response was potentiated by menthol (Fig. $2 F$ ), suggesting that they express TRPM8, whereas the other 3 were menthol-insensitive, suggesting a different cold transduction mechanism (Babes et al., 2004). Six of the eight responded to capsaicin. The percentage of CS neurons in adult TRPA1 ${ }^{-1-}$ mice $(13.2 \%$ in WT vs $11.6 \%$ in $\mathrm{KO})$ and the distribution of thermal thresholds were very similar to those found in adult wild-type animals [47\% HT-CS and 53\% LT-CS in WT $(n=45)$ vs $57 \%$ HT-CS and $43 \%$ LT-CS in KO $(n=21)$; $p=0.85$ ( $Z$ test) $]$.

These results suggest that TRPA1 ion channels of trigeminal ganglion neurons are not important for cold detection within a wide range of cold temperatures, in contrast with visceral neurons in which this channel appears to be the main determinant of cold sensitivity (Fajardo et al. 2008).

\section{Menthol effects are stronger in low-threshold CS neurons because of higher TRPM8 channel expression}

Menthol activates TRPM8 channels, shifting their thermal threshold (McKemy et al., 2002; Jordt et al., 2003; Voets et al., 2004). Menthol also activates TRPA1 (Karashima et al., 2007). As reported by Karashima et al. (2007), a fraction (56\%) of AITCsensitive neurons was also activated by menthol $(n=66)$ (Fig. $2 A$ ). Unlike the effects on TRPM8, in just 4 of these neurons ( $n=$ 37 ) was the response to cold sensitized by menthol. In the great majority $(89 \%)$ cooling inhibited the menthol response $(p<$ 0.01 ) (Fig. $2 B$ ), suggesting that menthol sensitivity in CS TG neurons is a reliable marker of TRPM8 expression.

Next we compared menthol effects between LT-CS and HT-CS neurons. In 46 LT-CS neurons, all except 3 (94\%) showed a robust increase in $\left[\mathrm{Ca}^{2+}\right]_{\mathrm{i}}$ (mean elevation of $214 \pm 24 \mathrm{nM}$ ) to applications of menthol $(100 \mu \mathrm{M})$ (supplemental Fig. S2A, available at www.jneurosci.org as supplemental material). In contrast, in 40 HT-CS neurons, menthol augmented $\left[\mathrm{Ca}^{2+}\right]_{\mathrm{i}}$ in only $62 \%$ of the cells ( $p<0.001, Z$ test) (see also Thut et al., 2003). Compared with LT-CS neurons, HT-CS neurons also showed significantly smaller calcium increments during cooling or menthol application (supplemental Fig. S2 A, available at www.jneurosci.org as supplemental material). Both temperature threshold and amplitude of the $\left[\mathrm{Ca}^{2+}\right]_{\mathrm{i}}$ increases in response to cold did not vary in either group of neurons with repeated cooling pulses in control condition. Failure of HT-CS 
to elevate $\left[\mathrm{Ca}^{2+}\right]_{\mathrm{i}}$ at basal temperature $\left(\sim 34^{\circ} \mathrm{C}\right)$ should not be interpreted as a lack of effect of menthol (supplemental Fig. S2 B, available at www.jneurosci.org as supplemental material). As a matter of fact, in all HT-CS neurons lacking a response to menthol at $34^{\circ} \mathrm{C}$, this drug shifted thermal threshold to warmer values (from a mean of $21.2 \pm 0.4^{\circ} \mathrm{C}$ to $\left.29.3 \pm 0.6^{\circ} \mathrm{C}, n=15\right)$, consistent with a sensitizing effect of menthol on TRPM8 channels (McKemy et al., 2002; Voets et al., 2004) (supplemental Fig. S2C, available at www.jneurosci.org as supplemental material). Only 2 CS neurons of 86 $(2.3 \%)$ were unresponsive to menthol (supplemental Fig. S2C, available at www. jneurosci.org as supplemental material).

From these findings we conclude that the large majority of trigeminal CS neurons, regardless of initial thermal threshold, express TRPM8 channels. Additionally, they also suggest variable TRPM8 expression levels among individual neurons.

\section{High TRPM8 expression levels are associated with low cold temperature thresholds}

Next, we asked whether expression levels of TRPM8 influence the temperature threshold. To this end, we established dose-response curves to different concentrations $(1-300 \mu \mathrm{M})$ of menthol in LT-CS and HT-CS neurons. Very low concentrations of menthol were able to evoke a clear $\left[\mathrm{Ca}^{2+}\right]_{\mathrm{i}}$ increase in LT-CS neurons, whereas responses in HT-CS neurons started at higher concentrations of menthol and were of smaller amplitude (Fig. $3 A$ ). The $\mathrm{EC}_{50}$ of menthol-induced $\left[\mathrm{Ca}^{2+}\right]_{\mathrm{i}}$ elevation was $5 \mu \mathrm{M}$ for LT-CS neurons $(n=37)$ and $272 \mu \mathrm{M}$ for HT-CS neurons $(n=13)$ (Fig. $3 B)$, suggesting that the former express higher TRPM8 levels.

A second, direct determination of functional TRPM8 channels was obtained with electrophysiological recordings during stimulation with cold $\left(I_{\text {cold }}\right)$ and cold plus $100 \mu \mathrm{M}$ menthol $\left(I_{\text {TRPM8 }}\right.$ ) (Fig. 3C). In LT-CS neurons, mean $I_{\text {cold }}$ was $-5.5 \pm 1.1$ $\mathrm{pA} / \mathrm{pF}(n=24)$. In contrast, in HT neurons $I_{\text {cold }}$ was significantly smaller (mean $=-0.4 \pm 0.3 \mathrm{pA} / \mathrm{pF}, n=22 ; p=0.0002, t$ test). LT-CS neurons had, on average, significantly higher densities of $I_{\text {TRPM } 8}$ than did HT-CS neurons $(-43.5 \pm 4.7 \mathrm{pA} / \mathrm{pF}: n=24 \mathrm{vs}$ $-12.8 \pm 3.0 \mathrm{pA} / \mathrm{pF}: n=22 ; p<0.0001, t$ test $)$. Overall, there was a positive correlation $(r=0.67 ; p<0.0001)$ between thermal threshold and amplitude of $I_{\text {TRPM } 8}$ in individual trigeminal neurons (Fig. 3D), suggesting that expression levels of TRPM8 influence the temperature threshold of cold thermoreceptors. A similar positive correlation was observed between $I_{\text {cold }}$ and thermal threshold in the same cells ( $r=0.63, p<0.0001$; data not shown).

Previously, we demonstrated that BCTC is a very effective blocker of cold-evoked currents in recombinant TRPM8 channels, lacking inhibitory actions on TRPA1 (Madrid et al., 2006). BCTC ( $1 \mu \mathrm{M}$, a dose blocking $\sim 70 \%$ of $I_{\text {cold }}$ in recombinant channels) caused a reversible shift in temperature threshold toward colder values in trigeminal neurons (supplemental Fig. $\mathrm{S} 3 A, B$, available at www.jneurosci.org as supplemental material). The thermal shift was more pronounced for LT-CS neurons compared with HT-CS $\left(4.6 \pm 0.5^{\circ} \mathrm{C}, n=24\right.$ vs $3.0 \pm 0.3^{\circ} \mathrm{C}, n=5$; $p<0.01$ ) (supplemental Fig. S3C, available at www.jneurosci.org as supplemental material), suggesting that in the former population, TRPM8 currents play a more important role in the determination of cold-evoked firing threshold.

Together, our data show that the population of LT-CS neurons has a higher sensitivity to menthol than have the HT-CS cells. This finding and the higher density of menthol-sensitive currents in LT-CS neurons strongly suggest that they express higher levels of TRPM8. A similar conclusion was reached previously in rat trigeminal (Thut et al., 2003) and dorsal root ganglion (DRG) (Xing et al., 2006) neurons.

\section{High $I_{\mathrm{KD}}$ expression levels are associated with high cold temperature thresholds}

$I_{\mathrm{KD}}$ is a voltage-dependent, slowly inactivating, 4-AP-sensitive $\mathrm{K}^{+}$current active at membrane potentials that are subthreshold for action potential generation (Storm, 1988; Viana et al., 2002). After obtaining a measure of the temperature threshold with $\mathrm{Ca}^{2+}$ imaging, we estimated the level of $I_{\mathrm{KD}}$ expression in wholecell voltage-clamp mode (see Materials and Methods). Figure $4 \mathrm{~A}$ presents recordings of two CS neurons representative of the LT and HT class. Both cells display a prominent noninactivating inward current during the hyperpolarizing voltage step. The properties of this current, and the blockade by 4 -(N-ethyl- $N$-phenylamino)-1,2-dimethyl-6-(methylamino)pyrimidinium chloride (ZD7288) (data not shown), are characteristic of the $I_{\mathrm{h}}$ current carried by HCN channels (Robinson and Siegelbaum, 2003). The record on the left is typical of a neuron with a high temperature threshold, $20^{\circ} \mathrm{C}$ in this particular case. The end of the hyperpolarizing step and the return of the membrane potential to -50 $\mathrm{mV}$ is accompanied by the appearance of a slowly decaying outward current (i.e., $I_{\mathrm{KD}}$ ). On the right a typical neuron with a low temperature threshold $\left(33^{\circ} \mathrm{C}\right)$ is shown. In this case, the return to the holding potential gives rise to a rapid inward tail current that 

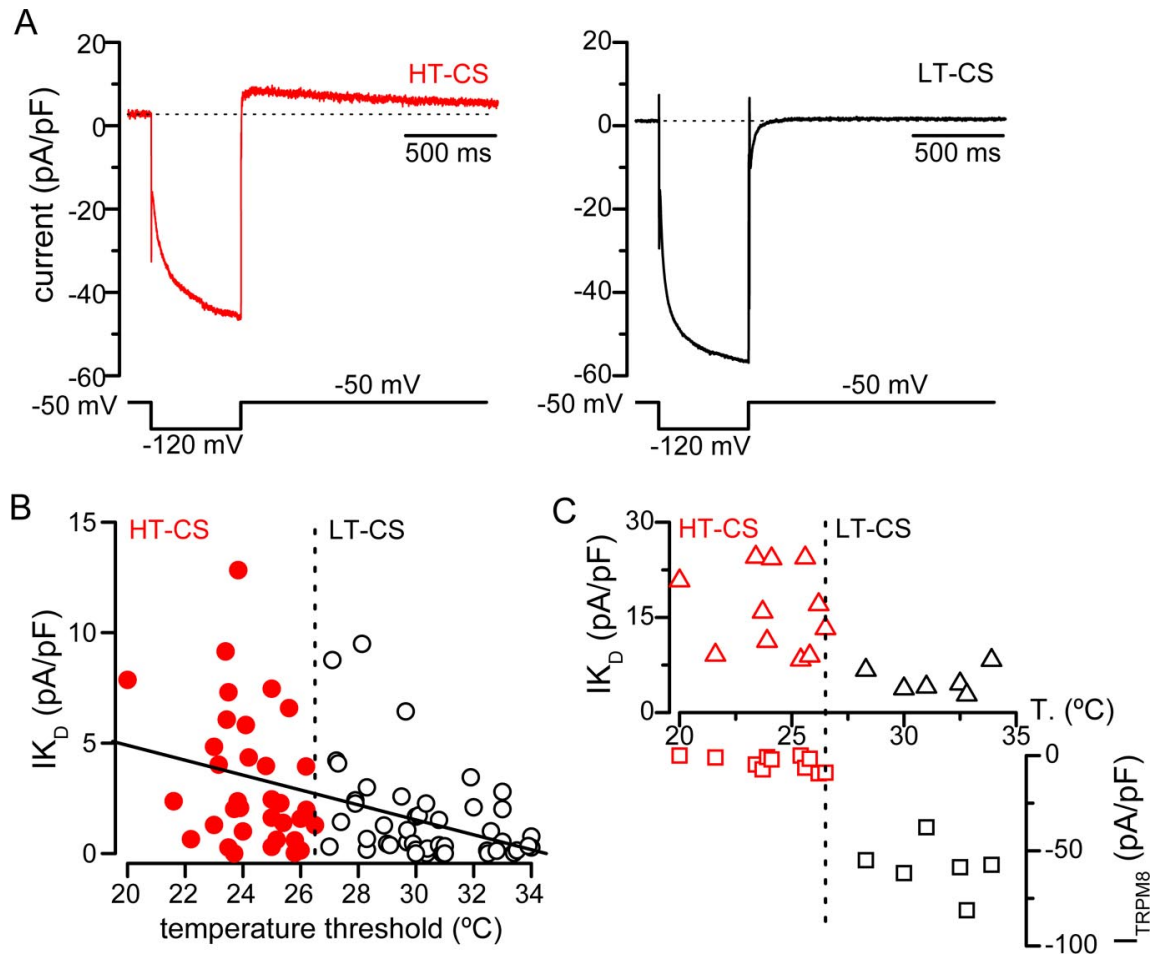

Figure 4. Differential $I_{\mathrm{KD}}$ expression in low-and high-threshold cold-sensitive neurons. $\boldsymbol{A}$, Whole-cell current response to a 500 ms hyperpolarizing voltage step to $-120 \mathrm{mV}$ from a holding potential of $-50 \mathrm{mV}$. Left, an HT-CS neuron (threshold $=20^{\circ} \mathrm{C}$ ). Right, An LT-CS neuron (threshold $=33^{\circ} \mathrm{C}$ ). $\boldsymbol{B}$, Correlation between threshold temperature and $I_{\mathrm{KD}}$ current density in $81 \mathrm{CS}$ neurons. $C$, Plot of $I_{\text {TRPM } 8}$ and $I_{K D}$ current density in individual $C S$ neurons. The abscissa represents the thermal threshold, measured with $\left[\mathrm{Ca}^{2+}\right]_{\mathrm{i}}$ imaging. $I_{\mathrm{KD}}$ was measured at $-40 \mathrm{mV}$ from a holding potential of $-120 \mathrm{mV}$, in the presence of $0.5 \mu \mathrm{M}$ TTX.

is suppressed by ZD7288 (data not shown), and no slowly decaying outward current was observed.

In the case of $I_{\mathrm{KD}}$, and opposite to the results for $I_{\mathrm{TRPM} 8}$, there was a negative correlation $(r=-0.44 ; p<0.0001)$ between temperature threshold and $I_{\mathrm{KD}}$ expression (Fig. $4 B$ ). On average, the amplitude of $I_{\mathrm{KD}}$ in HT-CS neurons was approximately twice as large as that in LT-CS neurons $(3.1 \pm 0.5 \mathrm{pA} / \mathrm{pF}$, in HT-CS neurons, $n=35$ vs $1.4 \pm 0.3 \mathrm{pA} / \mathrm{pF}$ in LT-CS neurons, $n=46$, $p=0.008, t$ test). In contrast, the density of $I_{\mathrm{h}}$ did not vary between HT-CS neurons and LT-CS neurons (28.7 \pm 3.7 vs $29.7 \pm 3.2 \mathrm{pA} / \mathrm{pF}, p=0.83)$. In a fraction of neurons $(n=17)$, we measured both currents, $I_{\mathrm{TRPM} 8}$ and $I_{\mathrm{KD}}$. Figure $4 C$ plots current densities as a function of thermal threshold for individual cells. The reciprocal pattern of $\mathrm{I}_{\mathrm{TRPM} 8}$ and $I_{\mathrm{KD}}$ current expression among LT- and HT-CS neurons is very obvious.

The $\mathrm{K}^{+}$channel blocker 4-AP produced a substantial block of $I_{\mathrm{KD}}$ (Fig. 5A). In $14 \mathrm{CS}$ neurons expressing $I_{\mathrm{KD}}, 100 \mu \mathrm{M} 4$-AP blocked $51.2 \pm 4.9 \%$ of the late outward current at $-40 \mathrm{mV}$. Blockade of $I_{\mathrm{KD}}$ produced a large, reversible shift in thermal threshold toward warmer temperatures (Fig. $5 B$ ). The average shift in threshold was larger $\left(10.5 \pm 0.9^{\circ} \mathrm{C}, n=10\right)$ in HT-CS neurons compared with LT-CS neurons $\left(3.3 \pm 0.6^{\circ} \mathrm{C}, n=14\right)$ $(p<0.01)$. In essence, all CS neurons, regardless of initial temperature threshold, were transformed into low-threshold CS neurons in the presence of low doses of 4-AP (Fig. $5 C$ ).

Altogether, our results indicate that $I_{\mathrm{KD}}$ is an important determinant of thermal threshold in trigeminal cold thermoreceptors and plays a major inhibitory role in cold sensitivity.
Kv1 channels are the molecular counterparts of $I_{\mathrm{KD}}$ in cold-sensitive neurons

We tested whether $\alpha$-DTx (Stühmer et al., 1989; Harvey and Robertson, 2004), a specific blocker of some Shaker potassium channel subunits (Kv1.1, Kv1.2, and Kv1.6) affected $I_{\mathrm{KD}}$ and thermal threshold in identified CS neurons. A $1 \mu \mathrm{M}$ concentration of $\alpha$-DTx blocked a slow outward current activated at subthreshold potentials (Fig. 5D). At $-40 \mathrm{mV}$ the block averaged $58 \pm 12 \%(n=3)$, very similar to the effects observed with $100 \mu \mathrm{M}$ 4-AP. Application of $\alpha$-DTx also produced a dosedependent (supplemental Table 1, available at www.jneurosci.org as supplemental material), reversible shift in the cold threshold of trigeminal neurons (Fig. $5 E, F)$. On average, $1 \mu \mathrm{M} \alpha$-DTx shifted the threshold by $2.7 \pm 0.6^{\circ} \mathrm{C}(n=19)$, a value that was nearly identical to the effect of 4-AP on the same neurons (mean shift $=3.0 \pm 0.6^{\circ} \mathrm{C} ; p=0.52$ ). Except in one case, the lack of effect of $\alpha$-DTx was paralleled by a lack of action of 4-AP (data not shown).

The effects of DTx-K, a related polypeptide that selectively blocks Kv1.1containing channels (Harvey and Robertson, 2004) on the cold threshold, were nearly identical to those observed with $\alpha$-DTx. On average, $1 \mu \mathrm{M}$ DTx-K shifted the threshold by $3.5 \pm 0.8^{\circ} \mathrm{C}(n=19)$ (supplemental Table 1, available at www.jneurosci.org as supplemental material).

TsTx, from the scorpion Tityus serrulatus, blocks Kv1.2 and Kv1.3-containing channels (Rodrigues et al., 2003). TsTx (100 $\mathrm{nM}$ ) also produced a significant shift in cold threshold (supplemental Table 1, available at www.jneurosci.org as supplemental material). Homotetrameric Kv1.1 and Kv1.2 show very different sensitivities to the $\mathrm{K}^{+}$channel blocker TEA, with the former being very sensitive $\left(\mathrm{IC}_{50}<0.5 \mathrm{~mm}\right)$, whereas the latter is virtually insensitive $\left(\mathrm{IC}_{50}>100 \mathrm{mM}\right)$, and with heteromeric channels falling in between (Christie et al., 1990). We tested 1-10 mM TEA on the cold sensitivity of TG neurons. The thermal shift produced by TEA was only significant at $10 \mathrm{~mm}$ (supplemental Table 1, available at www.jneurosci.org as supplemental material).

These results strongly suggest that dendrotoxins and 4-AP target the same population of voltage-gated $\mathrm{K}^{+}$channels. Given that Kv1.1 and Kv1.2 homotetrameric channels are essentially absent in the nervous system (Koschak et al., 1998; Manganas and Trimmer, 2000), it is likely that in CS neurons, $I_{\mathrm{KD}}$ is formed by a heteromer of Kv1.1 and Kv1.2, but additional Kv1 subunits cannot be excluded at present. Mean thermal shifts produced by all Kv1 blockers were always more prominent in HT-CS neurons, entirely consistent with a higher expression of $I_{\mathrm{KD}}$ in them (supplemental Table 1, available at www.jneurosci.org as supplemental material).

The biophysical properties of $I_{\mathrm{KD}}$ in CS neurons were characterized in detail, using standard biophysical protocols and pharmacological isolation of the current with 4-AP (Fig. 6A,B). $I_{\mathrm{KD}}$ starts to activate negative to $-50 \mathrm{mV}$, near the resting membrane 
A
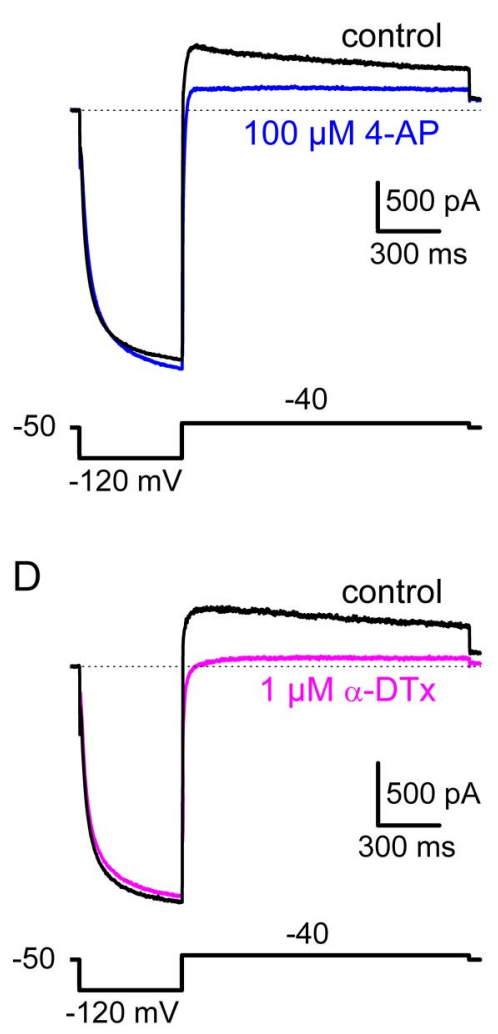

$\mathrm{B}$
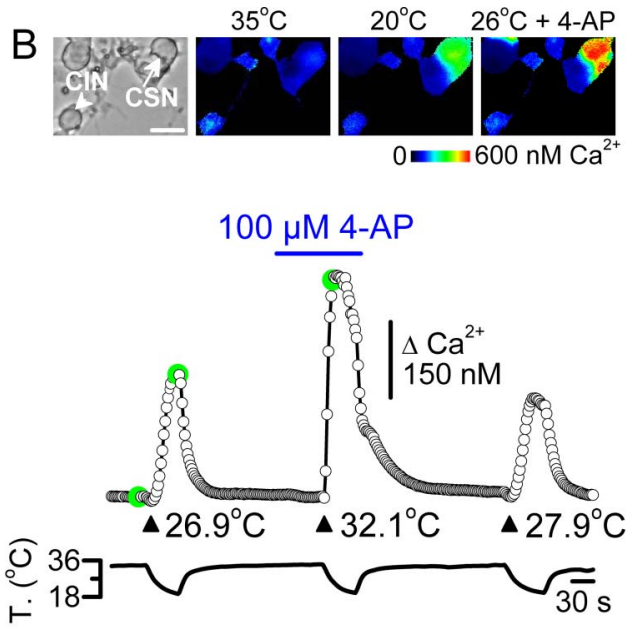

$E$

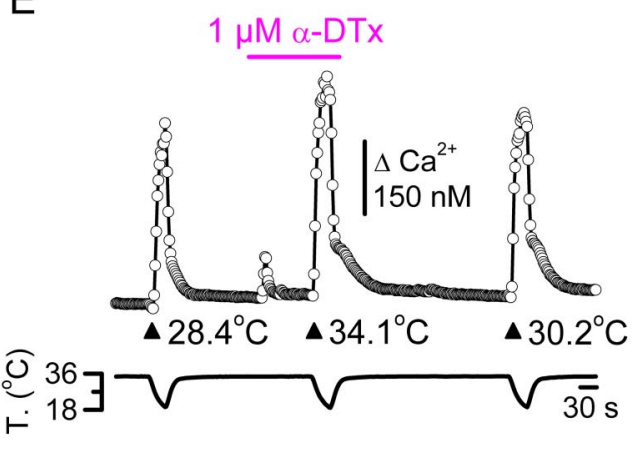

C

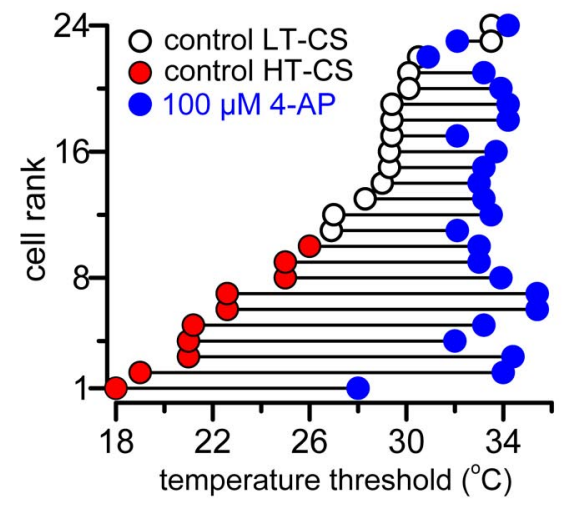

$F$

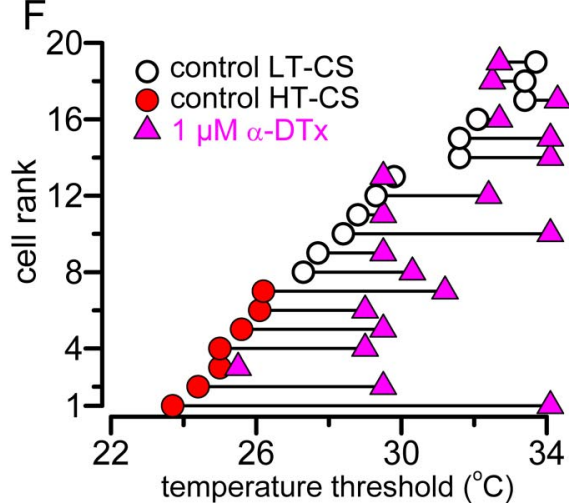

Figure 5. Thermal modulation of cold-sensitive neurons by 4-AP and $\alpha$-DTx. $A$, Whole-cell current in a CS neuron during a bipolar voltage step from -120 to $-40 \mathrm{mV}$ in control solution and in the presence of $100 \mu \mathrm{m}$ 4-AP. B, Effect of $100 \mu \mathrm{m}$ 4-AP on thermal threshold in a CS neuron. The green dots correspond to the pseudocolor images on the top row. $\boldsymbol{C}$, Summary of effect of $100 \mu \mathrm{m}$

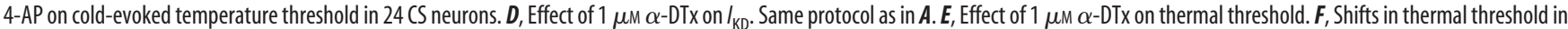
individual CS neurons $(n=19)$ produced by $1 \mu \mathrm{M} \alpha$-DTx.

potential of the cell, and the amplitude of the current increases steeply with voltage (Fig. 6C,D). The voltage for half-maximal activation $\left(V_{1 / 2}\right)$ of $I_{\mathrm{KD}}$ averaged $-13 \pm 2 \mathrm{mV}$, with a slope factor of $21 \pm 2(n=6)$. Inactivation is also voltage dependent (Fig. $6 E)$. The $V_{1 / 2}$ for steady-state inactivation curve averaged $-71 \pm 2$ $\mathrm{mV}$ and the slope, $-13 \pm 1(n=6)$, with a significant overlap between both curves, giving rise to a window current (Fig. $6 F$ ). The low activation threshold of $I_{\mathrm{KD}}$ and the slow inactivation imply that it will dampen the depolarizing influence of $I_{\text {TRPM }}$ during cooling, resulting in a higher thermal threshold and a reduction in the maximal response.

\section{Cold threshold is determined by the combined effects of $I_{\mathrm{KD}}$ and TRPM8}

Our results, so far, indicate that many CS trigeminal neurons express both $I_{\mathrm{TRPM} 8}$ and $I_{\mathrm{KD}}$, each of them having opposing actions on temperature threshold. This was tested directly in 20 neurons, applying blockers of TRPM8 and $I_{\mathrm{KD}}$ sequentially. The behavior of the cell shown in Figure 7A was typical of LT-CS neurons $(n=12)$, in this particular case, with a threshold of $33.4^{\circ} \mathrm{C}$. Application of $3 \mu \mathrm{M}$ BCTC produced a strong shift in threshold to colder temperatures, consistent with the potent inhibitory action of BCTC on TRPM8 channels (Madrid et al., 2006). Notably, perfusion with $75 \mu \mathrm{M} 4$-AP in the continuous presence of $3 \mu \mathrm{M}$ BCTC recovered most of the cold-evoked response with a threshold of $31.1^{\circ} \mathrm{C}$. In HT-CS neurons $(n=8), 3 \mu \mathrm{M}$ BCTC produced a full inhibition of the cold-evoked response (Fig. $7 B$ ), and coapplication of $75 \mu \mathrm{M} 4$-AP recovered the thermal sensitivity almost fully, suggesting that lowered TRPM8 activity can still evoke a thermal signal provided sufficient excitability brake is removed. The effects of sequential application of BCTC and 4-AP on thermal sensitivity of LT-CS (open circles) and HT-CS (red circles) are summarized in Figure 7C. In an additional set of 33 CS neurons, we applied the same blockers in the opposite sequence: first, $75 \mu \mathrm{M}$ 4-AP alone and thereafter combined with $3 \mu \mathrm{M}$ BCTC (Fig. 7D). As expected, application of 4-AP alone shifted the threshold to higher temperatures, whereas coapplication of 4-AP and BCTC shifted the threshold in the opposite direction (Fig. 7E). A similar, antagonistic effect was observed on the amplitude of coldevoked $\left[\mathrm{Ca}^{2+}\right]_{\mathrm{i}}$ signals (data not shown).

To confirm that the changes in temperature threshold produced by the blockers reflected real changes in neuronal excitability, we performed the same protocol during whole-cell current-clamp recordings. As shown in Figure $8 \mathrm{~A}$, application of $75 \mu \mathrm{M} 4$-AP to a CS neuron produced a strong shift in thermal threshold that was accompanied by a large increase in the number and frequency of action potentials during the cooling pulse. Notably, coapplication of 4-AP and $3 \mu \mathrm{M}$ BCTC fully reversed the shift in thermal threshold and the increased firing produced by 4-AP alone. The average results for 7 neurons are summarized in Figure 8, $B$ and $C$.

These results show that $I_{\mathrm{KD}}$ and $I_{\mathrm{TRPM} 8}$ exert opposite influences on cold temperature-dependent excitability. Furthermore, 
A

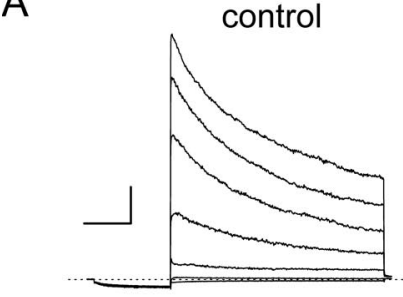

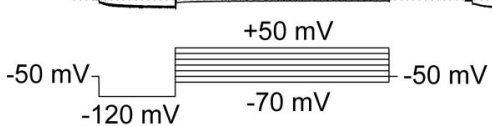

C

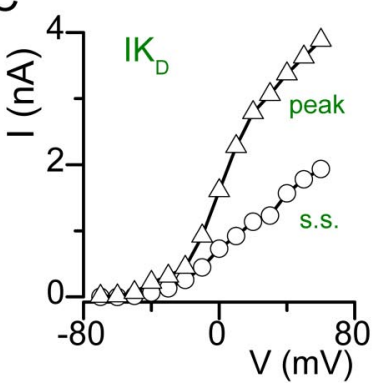

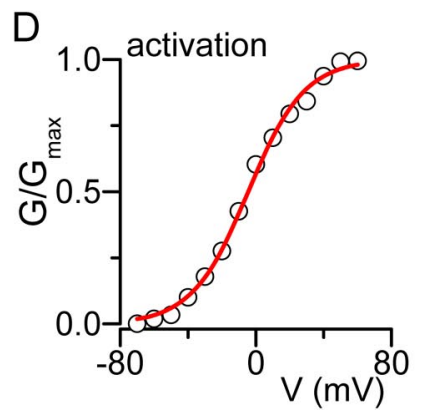

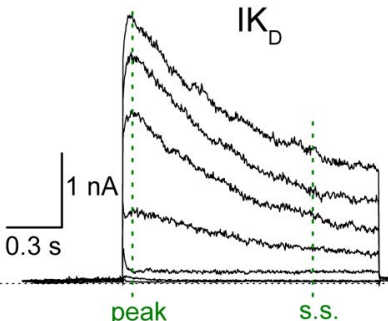

B

$100 \mu \mathrm{M} 4 \mathrm{AP}$

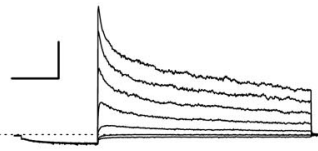

peak
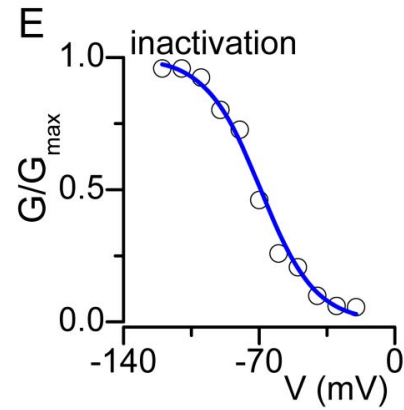

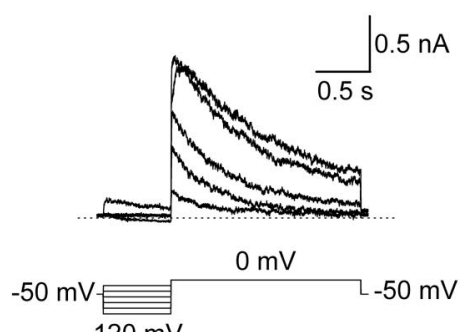

$-120 \mathrm{mV}$

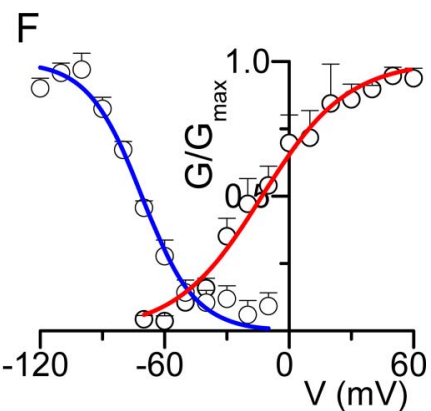

Figure 6. Pharmacological isolation and biophysical properties of $I_{\mathrm{KD}}$. $A$, Activation properties of whole-cell outward currents in a $\mathrm{CS}$ trigeminal neuron. The $0.5 \mathrm{~s} \mathrm{hyperpolarizing} \mathrm{prepulse} \mathrm{to}$ $-120 \mathrm{mV}$ was followed by a family of $1.5 \mathrm{~s}$ voltage steps that varied from -70 to $+60 \mathrm{mV}$ in $10 \mathrm{mV}$ increments (in the figure only alternate steps are represented). The records on the left were obtained in control external solution and those in the middle were obtained in the same cell after applying $100 \mu \mathrm{m} 4$ 4-AP. Digital subtraction of both sets of records yields the 4-AP-sensitive current (right panel). Note the very slow inactivation at negative membrane potentials. The absolute values of the calibration bars apply to the three panels. $\boldsymbol{B}$, Steady-state inactivation of the 4-AP-sensitive current (i.e., $\left.I_{\mathrm{KD}}\right)$. The voltage protocol is shown at the bottom. $C, I-V$ relationship of the peak and steady-state 4-AP-sensitive current. $D$, Activation curve of the 4-AP-sensitive current. The normalized conductance was fitted with a Boltzmann function with $V_{1 / 2}=-5 \mathrm{mV}$ and the slope factor $s=17$. $E$, Steady-state inactivation properties of the transient outward current. The data have been fitted to a Boltzmann function with $V_{1 / 2}=-71 \mathrm{mV}$ and the slope factor $s=-13$. Data for $\boldsymbol{A}-\boldsymbol{E}$ are from the same $\mathrm{CS}$ neuron (threshold $=25.4^{\circ} \mathrm{C}$ ). $\boldsymbol{F}$, Average activation and steady-state inactivation curves in $6 \mathrm{CS}$ neurons. Note the window current around the resting membrane potential.
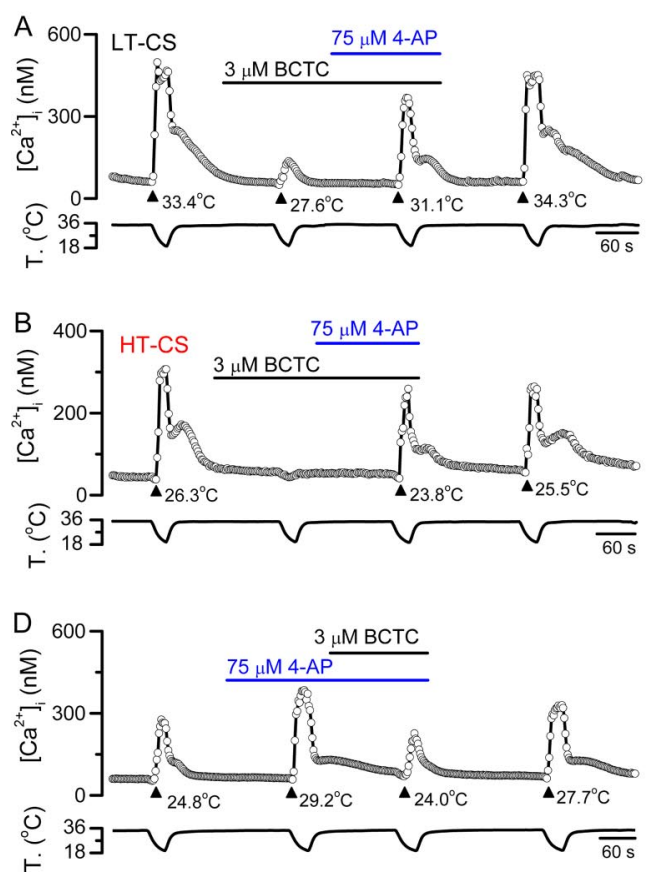

Figure 7. $I_{K D}$ and TRPM8 blockers exert an opposite influence on the thermal threshold of cold thermoreceptor neurons. $A$, Effect of $3 \mu \mathrm{M}$ BCTC alone and in combination with $75 \mu \mathrm{m}$ 4-AP on the amplitude and temperature threshold of an LT-CS neuron, evaluated with $\left[\mathrm{Ca}^{2+}\right]_{\mathrm{i}}$ imaging. $\boldsymbol{B}$, Same protocol as in $A$ but in an HT-CS neuron. $\boldsymbol{C}$, Histogram summarizing the effect of the different combinations of blockers on average thermal threshold for LT-CS (open circles) and HT-CS (red circles) neurons. Note the nearly full reversal of the inhibitory effect of $3 \mu \mathrm{m}$ BCTC by coapplication with $75 \mu \mathrm{m}$ 4-AP. D, Effect of $75 \mu \mathrm{m}$ 4-AP alone and in combination with $3 \mu \mathrm{MBCTC}$ on the amplitude and threshold of cold-evoked responses. $\boldsymbol{E}$, Summary of the effects of 4-AP and 4-AP plus BCTC on the thermal threshold of 33 CS neurons.
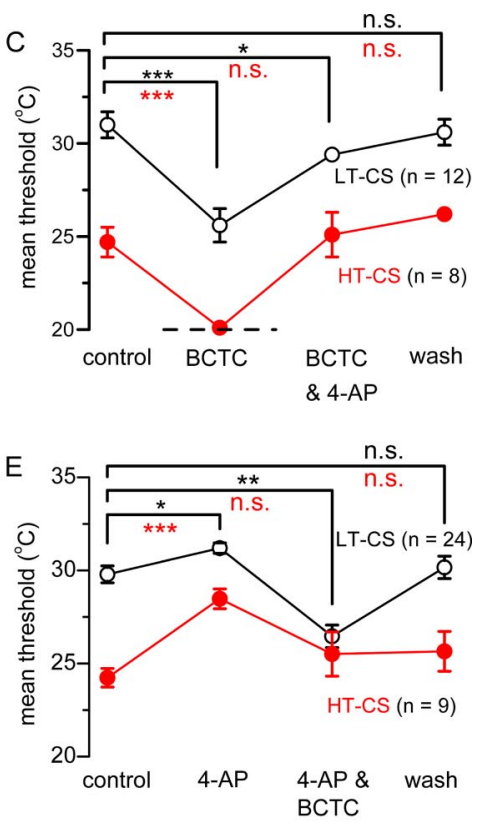

they indicate that thermal threshold and cold-evoked activity can be up- or downmodulated as a consequence of $I_{\mathrm{KD}}$ and TRPM8 function.

\section{Blockade of $I_{\mathrm{KD}}$ enhances cold-evoked} nocifensive behaviors

The observations presented in this study would predict that blockade of $I_{\mathrm{KD}}$ in cold nerve terminals in the intact animal would affect behavioral cold sensitivity. Indeed, local application of $I_{\mathrm{KD}}$ blockers (4-AP or $\alpha$-DTX) to the hindpaw in mice produced a significant increase in acute flinching responses to cold (acetone test) compared with preinjection control and compared with injection of vehicle, which had no effect (Fig. 9A). Furthermore, injection of 4 -AP or $\alpha$-DTX also reduced markedly the latency of nocifensive behavioral responses in the cold plate $\left(0^{\circ} \mathrm{C}\right)$ test (Fig. $\left.9 \mathrm{~B}\right)$. In contrast, application of either drug produced no changes in the hot plate test (Fig. 9C) or in mechanical thresholds for paw withdrawal (Fig. 9D). In TRPA1 ${ }^{-1-}$ mice, 4-AP and $\alpha$-DTX also produced marked increases in acetone-evoked flinching and reductions in the cold plate latency (Fig. 9A,B), suggesting that the mechanism behind the cold hyperalgesia observed is independent of TRPA1 expression. 
The fact that sensitization caused by 4 -AP and $\alpha$-DTx is restricted to cold and not to heat or mechanical stimulation, as would be expected if the drug had augmented the excitability of polymodal nociceptor endings, suggests that intense cold stimulates a population of high-threshold cold receptor neurons connected centrally with nociceptive pathways, which are distinct from polymodal (e.g., mechanoheat) nociceptor neurons. Specific blockade of $I_{\mathrm{KD}}$ with $\alpha$-DTx in mice increases sensitivity of these neurons to cold stimuli in such a way that nocifensive responses will thereafter be evoked with innocuous temperatures.

\section{Discussion}

Our data show that expression levels of TRPM8 and $I_{\mathrm{KD}}$ play a critical role in determining the thermal excitability of many low- and high-threshold trigeminal coldsensitive neurons. This proposal qualifies the view presented in many earlier studies (reviewed by Reid, 2005; Dhaka et al., 2006), which considered TRPM8 and TRPA1 channels as the specific receptors responsible for low- and high-threshold cold sensitivity, respectively. The evidence presented here suggests a more complex picture and, together with contributions of many recent studies (see below), emphasizes the need of rejecting conceptually attractive but oversimplified models of cold temperature sensing by peripheral neurons.

Our findings support the current canonical view that regards TRPM8 as a critical transducer for innocuous cold sensing. Thus, most low-threshold CS neurons were activated and/or sensitized by menthol. Furthermore, these cold responses were blocked by BCTC, an effective TRPM8 channel blocker with sensitizing actions on TRPA1 (Madrid et al., 2006; Fajardo et al., 2008). The majority of studies, including phenotypic analysis of TRPM8 knock-out mice, agree with this view (McKemy, 2005; Reid, 2005; Daniels and McKemy, 2007). In addition, we find that many high-threshold CS neurons also express TRPM8 (i.e., cold responses were sensitized by menthol and inhibited by BCTC) and provide a molecular explanation for their difference in threshold (see below). There is now growing morphological (Takashima et al., 2007), functional (Bautista et al., 2007; Xing et al., 2007), and behavioral evidence that TRPM8 also participates in sensing cold as unpleasant or painful (Green and McAuliffe, 2000; Acosta et al., 2001; Wasner et al., 2004; Namer et al., 2005; Green and Schoen, 2007). In this regard, it is most relevant that deletion of TRPM8 in mice produces a marked re$0.05)$. not shown).
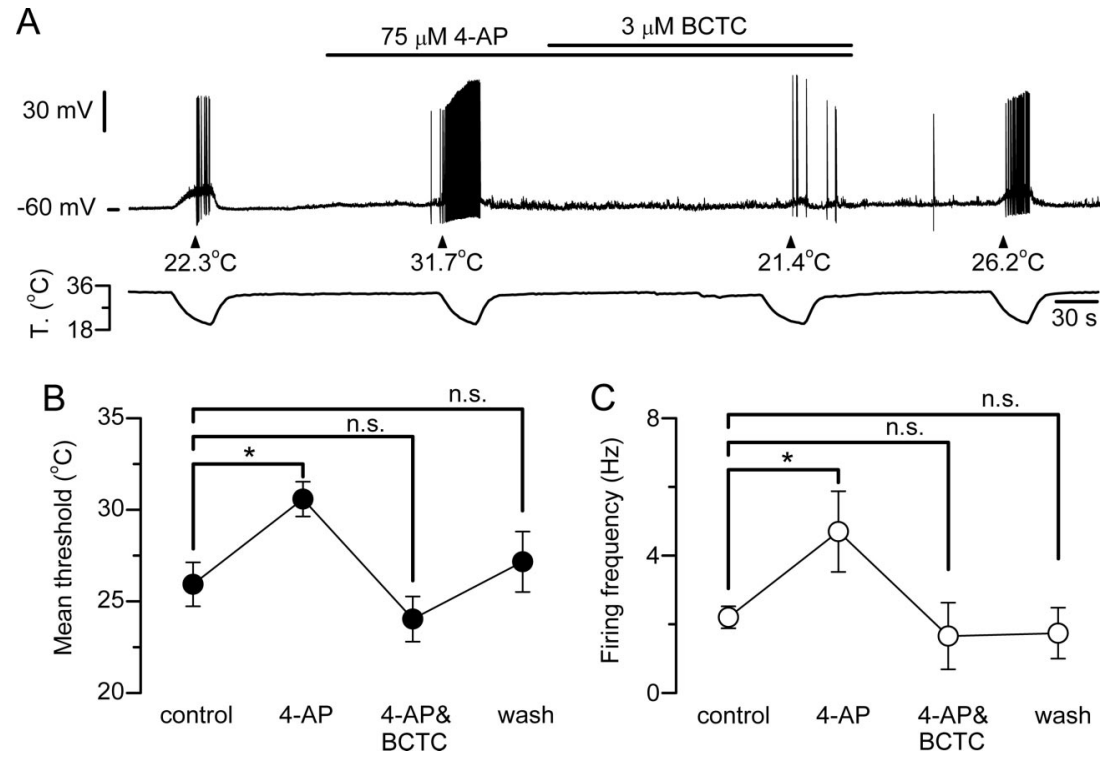

Figure 8. $I_{\mathrm{KD}}$ and TRPM8 exert an opposite influence on the thermal threshold and excitability of cold thermoreceptor neurons. $A$, Simultaneous recording of membrane potential (top trace) and bath temperature (bottom trace) during 4 consecutive cooling ramps in a cold-sensitive TG neuron recorded in perforated-patch current-clamp mode $\left(I_{\text {hold }}=0 \mathrm{pA}\right)$. Application of $75 \mu \mathrm{M}$ 4-AP shifted the temperature threshold and greatly enhanced the firing of action potentials during the cooling ramp. Coapplication of $75 \mu \mathrm{m}$ 4-AP with $3 \mu \mathrm{M} \mathrm{BCTC}$ produced a reversible reduction in the cold-induced depolarization and shifted the firing threshold toward lower temperature. $B$, Summary of the effects of 4-AP and 4-AP plus BCTC on the thermal threshold of 7 CS neurons. The shift in thermal threshold produced by $75 \mu \mathrm{m} 4-\mathrm{AP}$ averaged $4.7 \pm 1.4^{\circ} \mathrm{C}(p<0.05)$. C, Summary of the effects on mean firing frequency using the same protocol. Mean firing frequency was calculated by dividing by 10 the number of action potentials during a 10 s period after the first action potential evoked by cooling. The increase in firing produced by $75 \mu \mathrm{m} 4-\mathrm{AP}$ was significant $(p<$
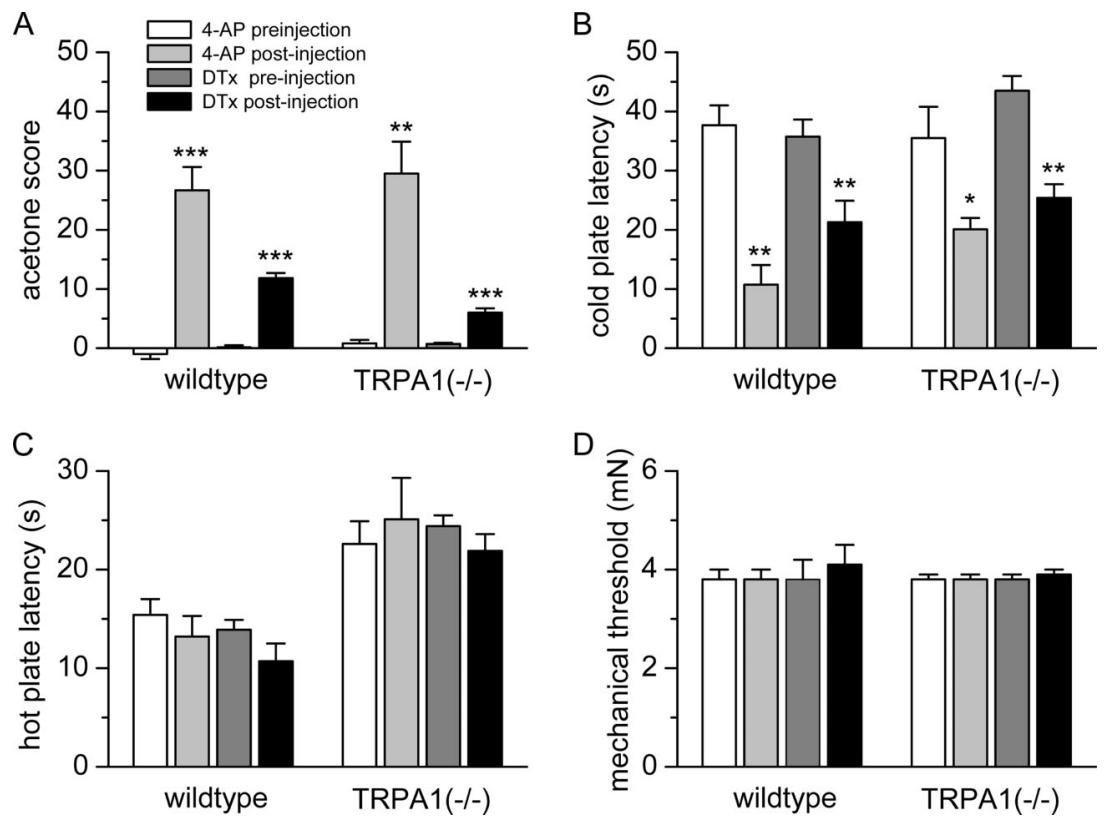

Figure 9. Blockade of $I_{K D}$ enhances cold-evoked nocifensive behaviors selectively. $\boldsymbol{A}$, Number of nocifensive behavior events in $1 \mathrm{~min}$ after application of acetone to the plantar surface of the hindpaw. Scores have been obtained before and after injection of $10 \mu \mathrm{l}$ of $10 \mathrm{~mm} 4$-AP or $100 \mu \mathrm{m} \alpha$-DTx to the hindpaw in wild-type $(n=6)$ and TRPA $1^{-1-}(n=4-8)$ animals. $B$, Cold plate $\left(0^{\circ} \mathrm{C}\right)$ withdrawal latency. $\boldsymbol{C}$, Hot plate $\left(52^{\circ} \mathrm{C}\right.$ ) withdrawal latency. $\boldsymbol{D}$, Withdrawal threshold to punctate mechanical stimuli (in millinewtons). In all cases, no differences in scores were observed before and after injection of $10 \mu$ l of vehicle to the hindpaw (data duction in the response of high-threshold cold-sensitive afferent fibers (Bautista et al., 2007), and reduces hyperalgesia to cold (Colburn et al., 2007). Early studies characterizing low- and highthreshold cold responses already signaled the strong overlap in 
their pharmacological characteristics: for example, both groups were menthol sensitive (Thut et al., 2003). We found no difference in the basic electrophysiological properties of LT- and HT-CS neurons, suggesting that they are part of the same ancestor pool of neurons, and that threshold differences between cold thermoreceptor neurons is determined by a rather specific mechanism.

Our results do not support the premise that the mechanism differentiating LT and HT trigeminal CS neurons is determined by TRPA1 expression; nor do they favor an important role of TRPA1 in the detection of unpleasant cold by uninjured mouse TG neurons. In our hands, only a very small percentage of TG CS neurons were activated by TRPA1 agonists. Moreover, cooling produced a significant inhibition of these agonist-evoked responses. Our observations agree fully with the results presented earlier by Jordt et al. (2004). These authors found that only $4 \%$ of mustard oil-sensitive TG neurons responded to cooling down to $5^{\circ} \mathrm{C}$. Similarly, in rat DRG neurons, Babes et al. (2004) found that HT-CS neurons were insensitive to mustard oil and concluded that TRPA1 is not involved in cold sensing in the temperature range between $32^{\circ} \mathrm{C}$ and $12^{\circ} \mathrm{C}$. However, in their study, the transducer for HT-CS neurons appeared to be different from TRPM8 because these neurons were not activated by menthol. Whether this means that cold-transducing mechanisms in DRG and TG are not identical should be clarified by future studies. Interspecies and methodological differences may also play a role. In particular, our cooling stimuli were relatively short in duration. We cannot exclude the idea that more intense or more sustained cooling stimuli may recruit additional cold-sensitive neurons with different phenotype (e.g., TRPA1 positive). In any case, it is very difficult to evaluate the physiological significance of cooling stimuli applied to the soma of neurons in culture, especially when their intensity and time course are far below the actual temperatures capable of evoking unpleasant and painful cold sensations when delivered to sensory nerve terminals in vivo, where overt pain is clearly evoked by external temperatures that do not reduce subcutaneous temperatures below $10^{\circ} \mathrm{C}$. The few TRPA1positive CS neurons we observed are most likely nociceptors involved in signaling the extreme cold temperatures that lead to burning pain (Morin and Bushnell, 1998; Davis and Pope, 2002). Results obtained in vivo by Simone and colleagues (Simone and Kajander, 1996, 1997) showed that all A $\delta$ - and C-type nociceptors are activated by cold at subzero temperatures.

Our findings do not imply that TRPA1 is irrelevant for all aspects of cold sensing. After peripheral nerve injury or inflammation, conditions that are accompanied by cold hyperalgesia, there is a clear involvement of TRPA1 in the functional and behavioral responses to cold (Katsura et al., 2006; Ji et al., 2008). Furthermore, our negative results for TRPA1 in TG neurons contrast with our own observation in nodose visceral neurons. In this case, the great majority of CS neurons, even those activated by relatively mild cold temperatures, were activated by TRPA1 agonists, whereas their cold response was blocked by TRPA1 antagonists (Fajardo et al., 2008). These findings were obtained under experimental conditions identical to those used in the present study. Thus, it is possible that tissue-specific posttranslational modifications or other factors influence the sensitivity of TRPA1 channels to temperature.

Finally, other studies have provided clear evidence for the contribution to cold sensing of additional mechanisms, independent of TRPM8 and TRPA1, such as closure of leak $\mathrm{K}^{+}$channels, and yet-to-be characterized mechanisms (Reid and Flonta, 2001; Viana et al., 2002; Babes et al., 2004, 2006; Munns et al., 2007). It is not unreasonable to speculate that many of these mechanisms will operate in concert in the intact animal, their relative contribution depending on a variety of factors such as final temperature at nerve endings, rate and duration of temperature reduction, metabolic state, and pathological conditions such as inflammation and nerve injury.

Our new findings on the expression pattern and molecular nature of $I_{\mathrm{KD}}$ expand our earlier description of a low-voltageactivated $\mathrm{K}^{+}$current acting as a molecular excitability break limiting the size of the subpopulation of cold-sensitive fibers (Viana et al., 2002; Roza et al., 2006). The blocking actions of DTx-K and tityustoxin-K $\alpha$ indicate that $\mathrm{Kv1} 1.1$ and $\mathrm{Kv1.2}$ are part of the channel complex forming $I_{\mathrm{KD}}$ (Wang et al., 1999; Harvey and Robertson, 2004) and excludes homomeric Kv1.2 channels, which are insensitive to DTx-K. Intriguingly, Kv1.1 knock-out mice show prominent cold-induced discharges in myelinated motor nerves (Zhou et al., 1998).

Altogether, our experimental evidence favors the view that detection of low temperatures in the psychophysical range of pleasant cooling to unpleasant cold is primarily performed by distinct subpopulations of cold thermoreceptors sharing a number of electrophysiological properties (i.e., short duration spikes, low rheobase, prominent $I_{\mathrm{h}}$ current) but thermally tuned by the variable expression of TRPM8 and Kv1 potassium channels and perhaps other thermosensitive channels whose excitatory and inhibitory influences will modulate the final thermal excitability. Both TRPM8 and Kv1 currents are present in sensory nerve endings (Kirchhoff et al., 1992; Madrid et al., 2006; Bautista et al., 2007), and some of these endings are excited by menthol and by low concentrations of 4-AP (Roza et al., 2006). Thus, we hypothesize that evolutionary forces sculpted a population of lowthreshold cold receptors with the following characteristics: high TRPM8 levels and low or absent $I_{\mathrm{KD}}$ expression. In contrast, specific high-threshold cold neurons would result from the following code: low TRPM8 levels and high expression of $I_{\mathrm{KD}}$. This population appears to be functionally distinct from conventional C-type polymodal nociceptor neurons that exhibit broad spikes and lack inward rectification (Scroggs et al., 1994; Fang et al., 2005). The high-threshold cold receptors we describe probably underlie the common sensation of unpleasant cold discomfort (Mauderli et al., 2003), accompanying, for example, sudden body immersion in cold water or exposure to very cold air. Polymodal nociceptors that appear to respond only to overtly injurious cold, and that elicit sensations of burning cold pain, may require more prolonged and/or deeper cooling for activation and require further study (Wahren et al., 1989; Simone and Kajander, 1997). An additional important player in the detection of noxious cold is the TTX resistant sodium channel (NaV1.8) (Akopian et al., 1996). Although this channel is apparently not essential for cold sensing, it is critical for propagation of nerve impulses at low temperatures (Zimmermann et al., 2007). In its absence, nociceptor sensory terminals become unexcitable at low temperatures, and it is attractive to speculate that this channel is also expressed by highthreshold cold thermoreceptors. A significant fraction of menthol- and cold-sensitive neurons in DRGs were found to express TTX-resistant sodium channels (Xing et al., 2006). A schematic representation of our proposal is illustrated in supplemental Figure 4, available at www.jneurosci.org as supplemental material.

Exacerbated cold sensitivity is a very frequent symptom after peripheral nerve injury (Jørum et al., 2003). Furthermore, coldevoked hyperalgesia is a disabling condition in postherpetic neuralgia (Pappagallo et al., 2000) and in neuropathies caused by 
cancer chemotherapy, often limiting the maximal dosage of prescribed antitumoral drugs (Lehky et al., 2004). These effects have been generally interpreted as the result of an altered processing of the information provided by low-threshold cold receptors and nociceptors at spinal cord neurons (Wahren et al., 1989). The data obtained in this work open the possibility that alterations in ion channels at peripheral terminals may additionally contribute to cold-evoked pain after nerve injury. Our findings indicate that disturbances of the expression ratio between peripheral TRPM8 and Kv1 potassium channels could give rise to hypersensitivity to cold through altered threshold and augmented excitability of specific high-threshold cold neurons, opening new therapeutic possibilities for alleviating this severely disabling, painful condition.

\section{References}

Acosta MC, Belmonte C, Gallar J (2001) Sensory experiences in humans and single-unit activity in cats evoked by polymodal stimulation of the cornea. J Physiol 534:511-525.

Akopian AN, Sivilotti L, Wood JN (1996) A tetrodotoxin-resistant voltagegated sodium channel expressed by sensory neurons. Nature 379:257-262.

Babes A, Zorzon D, Reid G (2004) Two populations of cold-sensitive neurons in rat dorsal root ganglia and their modulation by nerve growth factor. Eur J Neurosci 20:2276-2282.

Babes A, Zorzon D, Reid G (2006) A novel type of cold-sensitive neuron in rat dorsal root ganglia with rapid adaptation to cooling stimuli. Eur J Neurosci 24:691-698.

Bandell M, Story GM, Hwang SW, Viswanath V, Eid SR, Petrus MJ, Earley TJ, Patapoutian A (2004) Noxious cold ion channel TRPA1 is activated by pungent compounds and bradykinin. Neuron 41:849-857.

Bautista DM, Movahed P, Hinman A, Axelsson HE, Sterner O, Högestätt ED, Julius D, Jordt SE, Zygmunt PM (2005) Pungent products from garlic activate the sensory ion channel TRPA1. Proc Natl Acad Sci U S A 102:12248-12252.

Bautista DM, Jordt SE, Nikai T, Tsuruda PR, Read AJ, Poblete J, Yamoah EN, Basbaum AI, Julius D (2006) TRPA1 mediates the inflammatory actions of environmental irritants and proalgesic agents. Cell 124:1269-1282.

Bautista DM, Siemens J, Glazer JM, Tsuruda PR, Basbaum AI, Stucky CL, Jordt SE, Julius D (2007) The menthol receptor TRPM8 is the principal detector of environmental cold. Nature 448:204-208.

Chaplan SR, Bach FW, Pogrel JW, Chung JM, Yaksh TL (1994) Quantitative assessment of tactile allodynia in the rat paw. J Neurosci Methods 53:55-63.

Christie MJ, North RA, Osborne PB, Douglass J, Adelman JP (1990) Heteropolymeric potassium channels expressed in Xenopus oocytes from cloned subunits. Neuron 4:405-411.

Colburn RW, Lubin ML, Stone DJ Jr, Wang Y, Lawrence D, D'Andrea MR, Brandt MR, Liu Y, Flores CM, Qin N (2007) Attenuated cold sensitivity in TRPM8 null mice. Neuron 54:379-386.

Daniels RL, McKemy DD (2007) Mice left out in the cold: commentary on the phenotype of TRPM8-nulls. Mol Pain 3:23.

Davis KD, Pope GE (2002) Noxious cold evokes multiple sensations with distinct time courses. Pain 98:179-185.

Dhaka A, Viswanath V, Patapoutian A (2006) Trp ion channels and temperature sensation. Annu Rev Neurosci 29:135-161.

Dhaka A, Murray AN, Mathur J, Earley TJ, Petrus MJ, Patapoutian A (2007) TRPM8 is required for cold sensation in mice. Neuron 54:371-378.

Fajardo O, Meseguer V, Belmonte C, Viana F (2008) TRPAl channels mediate cold temperature sensing in mammalian vagal sensory neurons: pharmacological and genetic evidence. J Neurosci 28:7863-7875.

Fang X, McMullan S, Lawson SN, Djouhri L (2005) Electrophysiological differences between nociceptive and non-nociceptive dorsal root ganglion neurones in the rat in vivo. J Physiol 565:927-943.

Green BG (2004) Temperature perception and nociception. J Neurobiol 61:13-29.

Green BG, McAuliffe BL (2000) Menthol desensitization of capsaicin irritation. Evidence of a short-term anti-nociceptive effect. Physiol Behav 68:631-639.

Green BG, Schoen KL (2007) Thermal and nociceptive sensations from menthol and their suppression by dynamic contact. Behav Brain Res 176:284-291.
Harvey AL, Robertson B (2004) Dendrotoxins: structure-activity relationships and effects on potassium ion channels. Curr Med Chem 11:3065-3072.

Hensel H (1981) Thermoreception and temperature regulation. Monogr Physiol Soc 38:1-321.

Ji G, Zhou S, Carlton SM (2008) Intact Adelta-fibers up-regulate transient receptor potential A1 and contribute to cold hypersensitivity in neuropathic rats. Neuroscience 154:1054-1066.

Jordt SE, McKemy DD, Julius D (2003) Lessons from peppers and peppermint: the molecular logic of thermosensation. Curr Opin Neurobiol 13:487-492.

Jordt SE, Bautista DM, Chuang HH, McKemy DD, Zygmunt PM, Högestätt ED, Meng ID, Julius D (2004) Mustard oils and cannabinoids excite sensory nerve fibres through the TRP channel ANKTM1. Nature 427:260-265.

Jørum E, Warncke T, Stubhaug A (2003) Cold allodynia and hyperalgesia in neuropathic pain: the effect of $N$-methyl-D-aspartate (NMDA) receptor antagonist ketamine-a double-blind, cross-over comparison with alfentanil and placebo. Pain 101:229-235.

Karashima Y, Damann N, Prenen J, Talavera K, Segal A, Voets T, Nilius B (2007) Bimodal action of menthol on the transient receptor potential channel TRPA1. J Neurosci 27:9874-9884.

Katsura H, Obata K, Mizushima T, Yamanaka H, Kobayashi K, Dai Y, Fukuoka T, Tokunaga A, Sakagami M, Noguchi K (2006) Antisense knock down of TRPA1, but not TRPM8, alleviates cold hyperalgesia after spinal nerve ligation in rats. Exp Neurol 200:112-123.

Kirchhoff C, Leah JD, Jung S, Reeh PW (1992) Excitation of cutaneous sensory nerve endings in the rat by 4-aminopyridine and tetraethylammonium. J Neurophysiol 67:125-131.

Koschak A, Bugianesi RM, Mitterdorfer J, Kaczorowski GJ, Garcia ML, Knaus HG (1998) Subunit composition of brain voltage-gated potassium channels determined by hongotoxin-1, a novel peptide derived from Centruroides limbatus venom. J Biol Chem 273:2639-2644.

Kwan KY, Allchorne AJ, Vollrath MA, Christensen AP, Zhang DS, Woolf CJ, Corey DP (2006) TRPAl contributes to cold, mechanical, and chemical nociception but is not essential for hair-cell transduction. Neuron 50:277-289.

Lawson SN (2002) Phenotype and function of somatic primary afferent nociceptive neurones with C-, Adelta- or Aalpha/beta-fibres. Exp Physiol 87:239-244.

Lehky TJ, Leonard GD, Wilson RH, Grem JL, Floeter MK (2004) Oxaliplatin-induced neurotoxicity: acute hyperexcitability and chronic neuropathy. Muscle Nerve 29:387-392.

Madrid R, Donovan-Rodríguez T, Meseguer V, Acosta MC, Belmonte C, Viana F (2006) Contribution of TRPM8 channels to cold transduction in primary sensory neurons and peripheral nerve terminals. J Neurosci 26:12512-12525.

Manganas LN, Trimmer JS (2000) Subunit composition determines Kv1 potassium channel surface expression. J Biol Chem 275:29685-29693.

Mauderli AP, Vierck CJ Jr, Cannon RL, Rodrigues A, Shen C (2003) Relationships between skin temperature and temporal summation of heat and cold pain. J Neurophysiol 90:100-109.

McKemy DD (2005) How cold is it? TRPM8 and TRPA1 in the molecular logic of cold sensation. Mol Pain 1:16.

McKemy DD, Neuhausser WM, Julius D (2002) Identification of a cold receptor reveals a general role for TRP channels in thermosensation. Nature 416:52-58.

Morin C, Bushnell MC (1998) Temporal and qualitative properties of cold pain and heat pain: a psychophysical study. Pain 74:67-73.

Munns C, AlQatari M, Koltzenburg M (2007) Many cold sensitive peripheral neurons of the mouse do not express TRPM8 or TRPA1. Cell Calcium 41:331-342.

Namer B, Seifert F, Handwerker HO, Maihöfner C (2005) TRPA1 and TRPM8 activation in humans: effects of cinnamaldehyde and menthol. Neuroreport 16:955-959.

Nealen ML, Gold MS, Thut PD, Caterina MJ (2003) TRPM8 mRNA is expressed in a subset of cold-responsive trigeminal neurons from rat. J Neurophysiol 90:515-520.

Obata K, Katsura H, Mizushima T, Yamanaka H, Kobayashi K, Dai Y, Fukuoka T, Tokunaga A, Tominaga M, Noguchi K (2005) TRPA1 induced in sensory neurons contributes to cold hyperalgesia after inflammation and nerve injury. J Clin Invest 115:2393-2401. 
Pappagallo M, Oaklander AL, Quatrano-Piacentini AL, Clark MR, Raja SN (2000) Heterogenous patterns of sensory dysfunction in postherpetic neuralgia suggest multiple pathophysiologic mechanisms. Anesthesiology 92:691-698.

Peier AM, Moqrich A, Hergarden AC, Reeve AJ, Andersson DA, Story GM, Earley TJ, Dragoni I, McIntyre P, Bevan S, Patapoutian A (2002) A TRP channel that senses cold stimuli and menthol. Cell 108:705-715.

Perl ER (1996) Cutaneous polymodal receptors: characteristics and plasticity. Prog Brain Res 113:21-37.

Reid G (2005) ThermoTRP channels and cold sensing: what are they really up to? Pflugers Arch 451:250-263.

Reid G, Flonta M (2001) Cold transduction by inhibition of a background potassium conductance in rat primary sensory neurones. Neurosci Lett 297:171-174.

Robinson RB, Siegelbaum SA (2003) Hyperpolarization-activated cation currents: from molecules to physiological function. Annu Rev Physiol 65:453-480.

Rodrigues AR, Arantes EC, Monje F, Stühmer W, Varanda WA (2003) Tityustoxin-K(alpha) blockade of the voltage-gated potassium channel Kv1.3. Br J Pharmacol 139:1180-1186.

Roza C, Belmonte C, Viana F (2006) Cold sensitivity in axotomized fibers of experimental neuromas in mice. Pain 120:24-35.

Sawada Y, Hosokawa H, Hori A, Matsumura K, Kobayashi S (2007) Cold sensitivity of recombinant TRPA1 channels. Brain Res 1160:39-46.

Scroggs RS, Todorovic SM, Anderson EG, Fox AP (1994) Variation in IH, IIR, and ILEAK between acutely isolated adult rat dorsal root ganglion neurons of different size. J Neurophysiol 71:271-279.

Simone DA, Kajander KC (1996) Excitation of rat cutaneous nociceptors by noxious cold. Neurosci Lett 213:53-56.

Simone DA, Kajander KC (1997) Responses of cutaneous A-fiber nociceptors to noxious cold. J Neurophysiol 77:2049-2060.

Storm JF (1988) Temporal integration by a slowly inactivating K+ current in hippocampal neurons. Nature 336:379-381.

Story GM, Peier AM, Reeve AJ, Eid SR, Mosbacher J, Hricik TR, Earley TJ, Hergarden AC, Andersson DA, Hwang SW, McIntyre P, Jegla T, Bevan S, Patapoutian A (2003) ANKTM1, a TRP-like channel expressed in nociceptive neurons, is activated by cold temperatures. Cell 112:819-829.

Stühmer W, Ruppersberg JP, Schröter KH, Sakmann B, Stocker M, Giese KP, Perschke A, Baumann A, Pongs O (1989) Molecular basis of functional diversity of voltage-gated potassium channels in mammalian brain. EMBO J 8:3235-3244.

Takashima Y, Daniels RL, Knowlton W, Teng J, Liman ER, McKemy DD (2007) Diversity in the neural circuitry of cold sensing revealed by genetic axonal labeling of transient receptor potential melastatin 8 neurons. J Neurosci 27:14147-14157.

Thut PD, Wrigley D, Gold MS (2003) Cold transduction in rat trigeminal ganglia neurons in vitro. Neuroscience 119:1071-1083.

Viana F, de la Peña E, Pecson B, Schmidt RF, Belmonte C (2001) Swellingactivated calcium signalling in cultured mouse primary sensory neurons. Eur J Neurosci 13:722-734.

Viana F, de la Peña E, Belmonte C (2002) Specificity of cold thermotransduction is determined by differential ionic channel expression. Nat Neurosci 5:254-260.

Voets T, Droogmans G, Wissenbach U, Janssens A, Flockerzi V, Nilius B (2004) The principle of temperature-dependent gating in cold- and heatsensitive TRP channels. Nature 430:748-754.

Wahren LK, Torebjörk E, Jörum E (1989) Central suppression of coldinduced C fibre pain by myelinated fibre input. Pain 38:313-319.

Wang FC, Bell N, Reid P, Smith LA, McIntosh P, Robertson B, Dolly JO (1999) Identification of residues in dendrotoxin $\mathrm{K}$ responsible for its discrimination between neuronal $\mathrm{K}+$ channels containing Kv1.1 and 1.2 alpha subunits. Eur J Biochem 263:222-229.

Wasner G, Schattschneider J, Binder A, Baron R (2004) Topical menthol-a human model for cold pain by activation and sensitization of $\mathrm{C}$ nociceptors. Brain 127:1159-1171.

Xing H, Ling J, Chen M, Gu JG (2006) Chemical and cold sensitivity of two distinct populations of TRPM8-expressing somatosensory neurons. J Neurophysiol 95:1221-1230.

Xing H, Chen M, Ling J, Tan W, Gu JG (2007) TRPM8 mechanism of cold allodynia after chronic nerve injury. J Neurosci 27:13680-13690.

Zhou L, Zhang CL, Messing A, Chiu SY (1998) Temperature-sensitive neuromuscular transmission in Kv1.1 null mice: role of potassium channels under the myelin sheath in young nerves. J Neurosci 18:7200-7215.

Zimmermann K, Leffler A, Babes A, Cendan CM, Carr RW, Kobayashi J, Nau C, Wood JN, Reeh PW (2007) Sensory neuron sodium channel Nav1.8 is essential for pain at low temperatures. Nature 447:856-859.

Zurborg S, Yurgionas B, Jira JA, Caspani O, Heppenstall PA (2007) Direct activation of the ion channel TRPAl by $\mathrm{Ca}(2+)$. Nat Neurosci 10:277279 . 